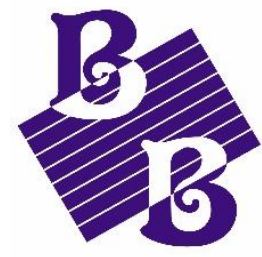

BioBacta
Journal of Bioscience and Applied Research www.jbaar.org

\title{
Molecular detection of food fraud targeting mitochondrial 12S rRNA gene sequencing
}

\author{
Sobhy El-Sayed Hassab El-Nabia ${ }^{a}$, Doaa Hussein ${ }^{\mathrm{b}}$, Asmaa Galal Khallaf ${ }^{\mathrm{a}}$ \\ ${ }^{a}$ Genetic Engineering and Molecular Biology Division, Department of Zoology, \\ Faculty of Science, Menoufia University, Egypt \\ ${ }^{b}$ Department of Zoology, Faculty of Science, Menoufia University, Egypt
}

\section{$3 *$ Corresponding author:}

Asmaa Galal Khallaf. E-mail: as_kh_22@yahoo.com. Tel: +201016446657.

DOI: 10.21608/jbaar.2021.167091

\begin{abstract}
Food adulteration is a current socioeconomic crisis all over the world. Therefore, the current study aimed to use the molecular sequencing of $12 \mathrm{~S}$ rRNA to detect food fraud in the most consumed meat cuts in the Egyptian markets. After sequences' trimming, the fragments' lengths were 389-395 bp for B. bubalis, B. taurus $O$. aries, and $C$. hircus. The results detected species substitution in the analyzed meat cuts. Particularly, buffalo and goat samples were replaced by cattle and buffalo. Finally, molecular methods are accurate and sensitive for the authentication of meat and are crucial in establishing the quality and authenticity of meat-based food products.
\end{abstract}

Keywords: FINS; Meat products; PCR-RFLP; sequencing; SNP; species identification; 12S rDNA.

\section{Introduction}

Meat discrimination and rapid detection of meat adulteration in different feedstuffs and foods deserve an increasing interest for many reasons, such as food allergies, religious affairs, and economic concerns (Farag et al., 2015). In addition, the identification of meat products a critical issue for controlling the meat industry and protect consumers from mislabeled and undesired meat products. This can be achieved by the determination of the presence of species substitutions and enforcing accurate food labeling.

In this context, many studies have developed various techniques for meat species identification. Among these techniques are the PCR-based methods, 
which are simple, accurate, and time-saving. Numerous DNA regions can be used as speciesspecific markers (Galal-Khallaf et al., 2016). It is noteworthy mentioning that the mitochondrial DNA was preferentially selected for molecular species identification as it provides many advantages compared to nuclear DNA (nDNA). Particularly, mitochondrial DNA (mtDNA) is present in multiple copies in cells increases the probability of detecting a specific sequence. In addition, the mitochondrial DNA is more resistant to degradation as it is circular DNA; this advantage increases the chance of amplifying undamaged DNA regions (Bottero \& Dalmasso, 2011). The mitochondrial cytochrome oxidase subunit 1 (COI) and 12S rDNA have been proved to be accurate markers for meat species discrimination (Chen et al., 2010; Haider et al., 2012; Mata et al., 2020). Therefore, this study aimed to utilize a molecular technique based on $12 \mathrm{~S}$ rRNA gene sequencing to detect meat adulteration of 4 meat species in the Egyptian markets.

\section{Materials and methods}

\subsection{Sampling}

Commercial fresh twenty meat cut samples of the most consumed red meat animals, i.e. cow, buffalo, sheep, goat (five samples/ each meat species) were purchased from local butchers at Menoufia governorate in Egypt. Butchers' names are not included in the present study. The sample's label details are included in table 1. A small tissue piece ( $100 \mathrm{mg}$ ) of all samples was kept in $96 \%$ ethanol and kept at $4^{\circ} \mathrm{C}$.

\subsection{DNA extraction}

Genomic DNA was isolated from meat samples (approximately $10 \mathrm{mg}$ ) by Chelex $^{\circledR}$ resin (SigmaAldrich, Germany). Briefly, samples were put in Eppendorf containing $500 \mu \mathrm{L}$ of $5 \%$ Chelex including
$3 \mu \mathrm{L}$ of proteinase $\mathrm{K}\left(400 \mathrm{U} \mathrm{mL}^{-1}\right)$. The tubes were incubated at $55{ }^{\circ} \mathrm{C}$ for 90 minutes. The Eppendorf tubes were transferred to $100^{\circ} \mathrm{C}$ for 20 minutes. Then, DNA was preserved at $-20{ }^{\circ} \mathrm{C}$ for subsequent analysis.

\subsection{PCR amplification and sequencing of $12 \mathrm{~S}$ rRNA gene}

Mitochondrial 12S rDNA partial fragment was amplified using Palumbi (1996) universal primers. The sequences of primers were as follows: 12SA: 5'-AAACTGGGATTAGATACCCCACTAT3. and 12SF: 5

GAGGGTGACGGGCGGGCGGTGTGT-3` . A $25 \mu \mathrm{L}$ amplification reaction was prepared to contain $2 \mu \mathrm{L}$ of DNA, $0.4 \mu \mathrm{M}$ of each primer, and $1 \mathrm{X}$ MyTaq $^{\mathrm{TM}}$ Red Mix (Bioline). The amplification reactions were run in a thermal cycler with the following conditions: initial denaturation at $95^{\circ} \mathrm{C}$ for $5 \mathrm{~min}$; followed by 35 cycles; each cycle consisted of denaturation step at $95{ }^{\circ} \mathrm{C}$ for $1 \mathrm{~min}$, annealing step at $57^{\circ} \mathrm{C}$ for $1 \mathrm{~min}$, and extension at $72{ }^{\circ} \mathrm{C}$ for $1 \mathrm{~min}$. 12S rDNA amplicons were separated on $1 \%$ ethidium bromide $\left(0.5 \mu \mathrm{g} \mu \mathrm{L}^{-1}\right)$ stained agarose gels. The PCR bands were visualized under an ultra-violet (UV) transilluminator. Finally, the PCR products were sent to Macrogen Inc. (Korea) for sequencing using the conventional Sanger sequencing method.

\subsection{Sequence analysis}

The 20 obtained sequences were corrected and edited manually using Chromas lite 2.1.1 software. For species identification, the sequences were compared to reference sequences in the GenBank database using the BLAST algorithm

(http://www.ncbi.nlm.nih.gov/genbank/). Cut-off values for $\%$ identity $>95 \%$ and alignment value $\mathrm{E} 1 / 4$ 0 were used for identification at species level. Using Mega X software (Kumar et al., 2018), the obtained sequences were aligned and trimmed. the haplotypes were determined by DNA Sequence polymorphism 
software (DnaSP) (Librado and Rozas, 2009) and then submitted to the GenBank database by Bank tool.

\section{Results}

\subsection{PCR and sequencing}

DNA was extracted from all commercial meat samples. PCR amplification of the 12S rRNA gene gave a single PCR product that was $~ 390$ bp long (figure 1). The PCR amplicons were good and pure enough for the sequencing step.

$12 \mathrm{~S}$ rRNA sequencing allowed unambiguous discrimination of all meat products analyzed in this study. All sequences exhibited the greatest identities ( $\geq 98 \%$ ) and the lowest e value with GenBank references.

\subsection{Molecular identification of meat samples of unknown origin}

In respect to the species of the analyzed meat samples, only the common name is available. Mitochondrial 12S rRNA sequencing allowed the identification of all samples at the species level. This study indicated the presence of a low level of mislabeling. Two out of 20 samples were mislabeled, whereas the remaining 18 samples were correctly labeled. Sequencing of $12 \mathrm{~S}$ rRNA confirmed that the identified species of 4 buffalo samples was B. bubalis. The remaining one buffalo sample was detected as Bos taurus. For cow samples, all samples were identified as Bos taurus. In addition, one goat sample was identified as Ovis aries. These findings indicated that there is an obvious violation of Egyptian law.

Table 1. Numbers and labels of meat cut samples and 12 rRNA gene sequencing results.

\begin{tabular}{llllll}
\hline & Samples' label & & \multicolumn{2}{c}{ 12S rRNA gene sequencing } & Mislabeling \\
\hline Samples & Common name & PCR amplicon & Identified species & BLAST identity (\%) & - \\
1B-4B & Buffalo & $389 \mathrm{bp}$ & Bubalis bubalis & $98 \%$ & + \\
5B & Buffalo & $389 \mathrm{bp}$ & Bos taurus & $98 \%$ & + \\
1C-5C & Cow & $389 \mathrm{bp}$ & Bos taurus & $98 \%$ & - \\
1G-4G & Goat & $390 \mathrm{bp}$ & Capra hircus & $99 \%$ & - \\
5G & Goat & $390 \mathrm{bp}$ & Ovies aries & $99 \%$ & + \\
1S-5S & Sheep & $395 \mathrm{bp}$ & Ovies aries & $99 \%$ & - \\
\hline
\end{tabular}




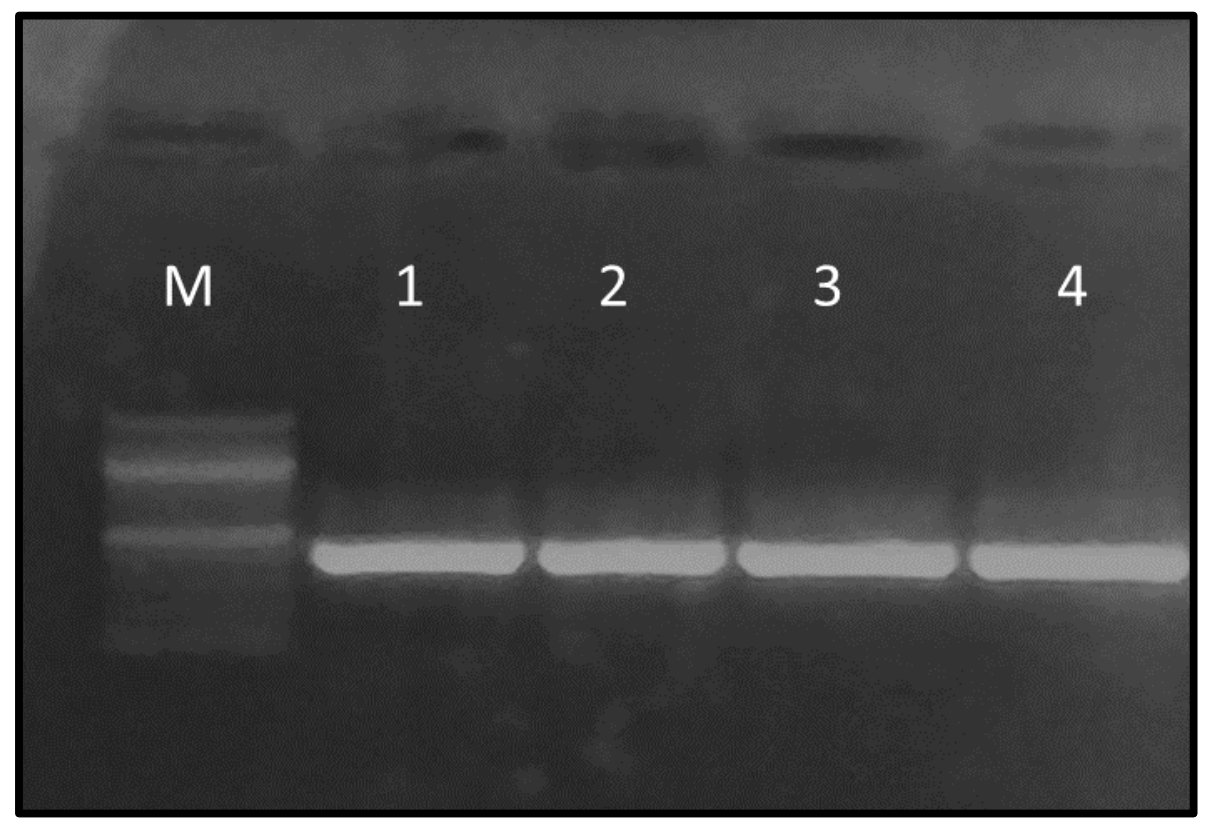

Figure 1. Agarose gel electrophoresis showing PCR products of mitochondrial 12S rRNA gene. M: Marker; 1: cow; 2: buffalo; 3: sheep; 4: goat.

\section{Discussion}

Consumer needs, economic requisites, or religious preferences all play a role in the identification of various animal species in meat products (He et al., 2018). When morphological characteristics are missing, consumers are unable to distinguish meat products. As a result, developing quick and accurate methodologies to identify organisms, avoid deliberate species substitutions, and ensure customer confidence is critical. Even though a variety of molecular methods have been used to authenticate the types of meat products, DNA-based techniques such as sequencing (Galal-Khallaf, 2021), DNA barcoding (Xing et al., 2020), and PCR-RFLP (Al et al., 2020) have a potential value for identifying meat animal species. The DNA-based methods are based on the inter-specific variation that exists among the identified species (Hajibabaei et al., 2007). Different mitochondrial markers are extensively used in meat authentication studies (Galal-Khallaf, 2021; Mane et al., 2014). The current study targeted the sequencing of a short mitochondrial fragment of the 12S rRNA gene because of its low inter-specific variability. $12 \mathrm{~S}$ rRNA gene sequencing using universal primers 
was effective enough to amplify and identify all meat cuts analyzed in this study. The current results revealed the presence of a low level of species substitution. In essence, one buffalo sample was replaced by a cow sample. Mahajan et al. (2011) used sequencing of 12S rRNA to indicate the substitution of 14 beef samples with buffalo. Similarly, another sample labeled as "goat" was detected to be "sheep". These replacements cannot be considered deliberate because this substitution may be due to the similarities in texture, taste, and color between beef and buffalo, which makes it difficult to differentiate between them. This replacement of buffalo with beef was previously unreported in Egypt. Moreover, goat replacement with sheep has been previously reported in the Amazonian regions due to the higher value of goat meat than sheep in these regions (Tafur-Culqui et al., 2020). Unlike Egypt, goats are economically more valuable than sheep due to the limited supply of goat meat in these regions (Tafur-Culqui et al., 2020). As a final remark, the present study suggested an accurate and applicable analytical method to identify meat products based on the sequencing of the mitochondrial 12S rRNA gene. As a result, Egyptian regulatory authorities will be able to rely on the applied methodology to keep track of meat products and enforce tighter labeling requirements.

\section{References}

Farag, M. R., Alagawany, M., Abd El-Hack, M. E., Tiwari, R., \& Dhama, K. (2015). Identification of different animal species in meat and meat products: trends and advances. Adv. Anim. Vet. Sci, 3(6), 334-346.
Galal-Khallaf, A., Ardura, A., Borrell, Y. J., \& Garcia-Vazquez, E. (2016). PCR-based assessment of shellfish traceability and sustainability in international Mediterranean seafood markets. Food Chemistry, 202, 302308.

Bottero, M. T., \& Dalmasso, A. (2011). Animal species identification in food products: Evolution of biomolecular methods. The Veterinary Journal, 190(1), 34-38.

Chen, S. Y., Liu, Y. P., \& Yao, Y. G. (2010). Species authentication of commercial beef jerky based on PCR-RFLP analysis of the mitochondrial $12 \mathrm{~S}$ rRNA gene. Journal of Genetics and Genomics, 37(11), 763-769.

Haider, N., Nabulsi, I., \& Al-Safadi, B. (2012). Identification of meat species by PCR-RFLP of the mitochondrial COI gene. Meat Science, 90(2), 490-493.

Mata, W., Chanmalee, T., Punyasuk, N., \& Thitamadee, S. (2020). Simple PCR-RFLP detection method for genus-and speciesauthentication of four types of tuna used in canned tuna industry. Food Control, 108, 106842.

Palumbi, S. R. (1996). Nucleic acids II: The polymerase chain reaction. In D. M. Hillis, C. Mortiz, \& B. K. Mable (Eds.), Molecular systematic (2nd ed, pp. 205-247). USA: Sinauer Associates Inc.

He, H., Wang, Y., Qing, Y., Li, D., Zhao, X., Zhu, Q., \& Yin, H. (2018). Molecular Authentication of Meats from Three Terrestrial Birds Based on Pcr-Rflp Analysis of the Mitochondrial 12S rRNA Gene. Brazilian Journal of Poultry Science, 20(4), 651-656.

Galal-Khallaf, A. (2021). Multiplex PCR and 12S rRNA gene sequencing for detection of meat 
adulteration: A case study in the Egyptian markets. Gene, 764, 145062.

Hajibabaei M, Singer GA, Hebert PD, Hickey DA. DNA barcoding: how it complements taxonomy, molecular phylogenetics, and population genetics. Trends in Genetics 2007;23(4):167-172

Mane, B. G., Mendiratta, S. K., Raut, A. A., \& Tiwari, A. K. (2014). PCR-RFLP assay for identification of species origin of meat and meat products. Journal of Meat Science and Technology, 2(2), 31-36.

Tafur-Culqui, J., Calderon, M. S., \& Bustamante, D. E. (2020). Identification of commercial meats from Amazonas, Peru using PCR-RFLP of mitochondrial $12 \mathrm{~S}$ rRNA gene. Brazilian Journal of Food Technology, 23, doi.org/10.1590/1981-6723.27419.

He, H., Wang, Y., Qing, Y., Li, D., Zhao, X., Zhu, Q., \& Yin, H. (2018). Molecular Authentication of Meats from Three Terrestrial Birds Based on Pcr-Rflp Analysis of the Mitochondrial 12S rRNA Gene. Brazilian Journal of Poultry Science, 20(4), 651-656. 